suele ser habitual, por la representación de un anillo o diadema, ambos artistas optan por colocar encima de la coronilla una especie de disco; otra coincidencia con esta obra de Mantegna es el modo en que las columnas que conforman la arquitectura de las escenas se abren escalonadamente al paisaje del fondo. Sin embargo, nos parece que en las tablas de Berrueces la influencia italiana es eminentemente umbra, en loś paisajes y en la gran preocupación espacial, como ya se ha dicho, pero también en la blanda dulzura de los tipos humanos. El Quattrocento umbro se simplifica con frecuencia centrándolo únicamente en la figura de Perugino. Pero hay artistas como Pinturicchio, formado en el taller del primero, que tiene una personalidad propia. Es más colorista, más decorativo, hace un mayor uso del oro que el resto de sus contemporáneos y sus figuras imitan las de Perugino, pero dotándolas de una mayor languidez. Todas estos rasgos encajan muy bien con el gusto español, por lo que no es extraño que hallemos una fuerte influencia de su obra dentro de nuestras fronteras. En este retablo es evidente en el tratamiento espacial, en la dulzura de sus rostros, y hasta en una de los detalles más peculiares del Maestro de Astorga, su gusto por colocar los rostros de modo oblicuo o simplemente con la cabeza ladeada. Esta característica no es sino la traducción de la expresión de los rostros de las pinturas de Pinturicchio - también de Perugino- que quieren evocar sorpresa o esa gracia lánguida a la que nos referíamos antes. El efecto de esta traslación de gestos en la obra del Maestro de Astorga resulta a veces un tanto caricaturesco por la inferioridad de talento frente a sus modelos italianos, pero en cambio nos permite apoyar su autoría en muchas ocasiones.

Respecto a su datación, teniendo en cuenta que el retablo princeps tiene inscrita la fecha de 1530 en la parte baja del banco ${ }^{20}$, nos inclinamos por considerar muy ligeramente posteriores las tablas de Berrueces por su madurez en el tratamiento espacial y su mayor italianismo observado en la suavidad de los colores, en las arquitecturas renacientes y en las figuras, pese al arcaismo que representan los nimbos dorados. De todos modos, son unas pinturas muy ancladas en el Quattrocento para lo avanzado de la fecha, pero esto es algo habitual en la pintura de Tierra de Campos hasta la llegada del lenguaje manierista de la mano de Alonso Berruguete.

IRUNE Fiz FuerTes

Universidad de Valladolid

\title{
CLAUDIO COELLO DECORADOR MURAL: A PROPÓSITO DE UN PROYECTO SUYO PARA LA DECORACIÓN DE UN MURO DE CAPILLA
}

Aspecto todavía poco conocido de la producción artística de Claudio Coello (1642-1693) es, sin duda, su labor como decorador mural ${ }^{~}$. Aunque no es mucho lo que se conserva de sus

${ }^{20}$ Gómez Moreno, Manuel: Catálogo monumental de la provincia de León. Madrid, 1925, p. 331.

\footnotetext{
${ }^{1}$ Los estudios monográficos que se han dedicado a esta especialidad de Coello son escasos, limitándose tan sólo a varios artículos importantes y a algunas referencias en sus monografías como artista, entre ellos: E. Tormo, «Actualidad lamentable. Frescos de Coello, Cabezalero y otros, derribados en San Plácido», La Esfera, 6 de marzo de 1908; M. Chamoso Lamas, «Las pinturas de las bóvedas en la Mantería de Zaragoza, obra de Claudio Coello y de Sebastián Muñoz», Archivo Español de Arte (A.E.A.), 1944, pp. 370-382; J.A. Gaya Nuño, Claudio Coello, Madrid 1957, pp.10-13, 18-20; E. J. Sullivan, «Two paintings by Claudio Coello in Valdemoro and his work for the Jesuits in Madrid», Studia Graculatoria, Madrid 1979, 259-266; Id., Claudio Coello y la pintura barroca madrileña, Ed. Española 1989, pp.73-76, 82-84, 101-102, 188-190, 203-205, 241-242.
}

AEA, LXXV, 2002, 300, pp. 407 a 446 
pinturas murales ${ }^{2}$, las fuentes que poseemos de ellas ${ }^{3}$ y la existencia de algunos dibujos suyos para la decoración de paramentos y techos ${ }^{4}$, indican que su actividad en este género fue tan relevante como la de caballete.

El proyecto que estudiamos a continuación, la Decoración de un muro de capilla mayor dedicado a la Inmaculada Concepción de María, se suma pues a este intento de conocer mejor la obra de Coello como decorador mural.

Formado con Francisco Rizi, en la técnica del temple y del fresco, «por haber asistido a su maestro - según Palomino- en obras de todas calidades» ${ }^{5}$, su estilo como decorador se fraguó en la moda italiana de la «quadratura» o de las perspectivas fingidas, difundidas entre nosotros por los fresquistas italianos Mitelli y Colonna que habían sido llamados a la Corte por Velázquez para decorar en 1658 el admirable Salón de los Espejos del Alcázar ${ }^{6}$.

Rizi, junto a Carreño intervinieron en esta importante empresa decorativa, cuando Coello se encontraba todavía como aprendiz, por lo que no es demasiado aventurar - siguiendo el relato de Palomino- que Claudio, ya con dieciséis años ${ }^{7}$, asistiese a este evento artístico, tan decisivo para la continuación de nuestra pintura decorativa seiscientista.

Coello, por tanto, se forma ya desde su aprendizaje como pintor decorador mural, y gran parte de su repertorio a lo italiano - perspectivas fingidas, rompimientos de celajes, mascarones, hojas, tarjas, cornucopias, etc. - será el habitual a lo largo de toda su trayectoria como decorador.

Pero el estilo de Claudio Coello como pintor de bóvedas y muros, se debió nutrir también a través de su más estrecho colaborador en este tipo de empresas decorativas: José Jiménez Donoso (h.1632-1690) ${ }^{8}$, quien, formado en Roma durante siete años como «pintor, perspectivo, y consumado arquitecto» ${ }^{9}$, hubo de enriquecer seguramente el estilo de su coetáneo aportando novedades italianas del pleno barroco cortonesco y berninesco.

Esta «asociación» profesional «Coello-Donoso», cuyo inicio debemos fechar a mediados de los sesenta ${ }^{10}$, aproximadamente, acaparó los encargos más importantes de Madrid y provincias limítrofes, prolongándose hasta principios de los ochenta ${ }^{11}$, para pasar luego a una fase

\footnotetext{
${ }^{2}$ Se limitan solamente al Techo del Vestuario de la Catedral de Toledo(h. 1671-1674), a los testimonios del Colegio Imperial de los Jesuitas: el Techo destruido de la Capilla de San Ignacio, (conocido sólo por una fotografía y un estudio preparatorio) y los restos aún visibles de la Capilla del Cristo(h.1671-1673), al Techo del Salón Real de la madrileña Casa de la Panadería(h.1762-1674) y a las Bóvedas de la iglesia zaragozana de San Roque (La Mantería)(1685).

${ }^{3}$ Se resumen principalmente a tres: A.A. Palomino y Velasco, Museo Pictórico y Escala Óptica con el Parnaso Español Pintoresco Laureado, Madrid 1715-1724, ed. Aguilar 1988, t.3, Vida 186, pp.450-460; A. Ponz, Viaje de España, Madrid 1772-1794, ed. Aguilar 1988 y J.A. Ceán Bermúdez, Diccionario histórico de los más ilustres profesores de las Bellas Artes en España, Madrid 1800, ed. facsímil en 1965, T.1, pp.336-347. Sobre documentos que hacen referencias a pagos de pinturas murales véase la recopilación hecha por Sullivan, Ob. cit., 1989, Apéndice 4, pp.306-308.

${ }^{4}$ Se compilan en Sullivan, Ob. cit., 1989, capítulo Dibujos: atribuciones aceptadas, núms. d6-d7, d10, d21, d24, d26-d28, d41, d43-d44, d46-d49, d52-d53.

${ }^{5}$ Palomino, Ob. cit., T.3, p. 451

${ }^{6}$ Sobre este aspecto véase A. Bonet Correa, «Velázquez, arquitecto y decorador» A.E.A. 1960, pp.215-249.

${ }^{7}$ Según Palomino (Ob.cit.T.3, p.450) que le conoció, entró en el taller de Rizi a los doce o trece años, es decir, hacia 1654-1655. Como es sabido, en aquel entonces el tiempo oficial de aprendizaje se estipulaba en unos cinco años, por lo que es muy probable que su formación finalizase hacia 1660.

${ }^{8}$ Sobre este pintor «aún no suficientemente estudiado» véase A. Pérez Sánchez, Pintura barroca en España. 1600-1750, Madrid, 1992, pp.321-322, donde se recoge bibliografía específica.

${ }^{9}$ Palomino, Ob. cit., T.3, p. 419

${ }^{10}$ La primera obra en la que trabajan juntos fue al parecer el techo del presbiterio de la Iglesia madrileña de Santa Cruz, de hacia 1667 (destruido) (Palomino, Ob. cit., T.3, p. 452).

"A lo largo de este periodo que abarca unos trece o catorce años trabajaron juntos en el Vestuario de la Catedral de Toledo (h. 1671-1674), en el Colegio imperial de la Corte (h. 1671-1673), en el Monasterio de Santa María del Paular (h. 1672) según Palomino(p.453), en el Salón Real de la madrileña Casa de la Panadería (h. 1762-1674), en la ¿Capilla madrileña de San Francisco de Borja? (1678), en las decoraciones palaciegas que se hicieron en los aposentos de la reina Maria Luisa de Orleáns con motivo de su entrada en Madrid (1679), y en las iglesias madrileñas de los Trinitarios Calzados y San Basilio (ambas de h. 1680)
}

AEA, LXXV, 2002, 300, pp. 407 a 446 
decorativa mural en solitario ${ }^{12}$, tras la que se continuaron otros trabajos con pintores, como Sebastián Muñoz, Palomino, Arredondo y Jan van Kessel, ya al final de su vida ${ }^{13}$.

El presente proyecto inmaculadista, dadas sus características como estudio y su probable cronología en torno a 1680, podría ser una actuación más de Claudio Coello como decorador mural en solitario.

La composición, de singular perfección y maestría, se conoce gracias a dos dibujos que son prácticamente iguales salvo en su ejecución técnica. Uno, dado a conocer por Pérez Sánchez en 1972, mide 436 por $270 \mathrm{~mm}$. y se conserva en el Gabinetto Disegni e Stampa degli Uffizi de Florencia ${ }^{14}$ (Fig. 1). Está realizado a pluma, con tinta marrón y aguada gris sobre trazos de lápiz negro, y presenta una cuadriculación, también a lápiz negro, que refleja el último estadio de una composición realizada con la intención de ser llevada a cabo. El otro, de medidas similares: 432 por 266 mm., se conserva en la Biblioteca Nacional de Madrid (Fig. 2), y fue catalogado por Barcia como de Coello en 1906 sin conocer probablemente la existencia del otro dibujo ${ }^{15}$. Está realizado a pluma con tinta marrón y gris, y su ejecución técnica difiere sensiblemente del de Florencia en el modo de tratar la pluma en los contornos, mucho más precisos aquí, y en la ausencia de la cuadriculación a lápiz, lo que unido a las medidas casi idénticas de ambos, hace sospechar que el de Florencia sea el original (u herramienta, o modelo del pintor) y el de Madrid una copia realizada probablemente mediante «calco» ${ }^{16}$, acaso para el contrato o comitente.

Uno de estos dos dibujos poseyó el pintor Jerónimo Ezquerra ${ }^{17}$, tal como consta en su inventario de bienes realizado en 1733. En dicho inventario se registra con el número 413 «Otro dibujo de un retablo de la Conzepción de mano de Don Claudio Cuello» ${ }^{18}$. La seguridad en su atribución hace pensar que el dibujo consignado fue el original de Florencia, pues lleva en la parte inferior una inscripción con letra del siglo xvir que indica la autoría con el nombre de «Claudio» (acaso firma del propio pintor).

El proyecto como tal comprende la decoración frontal de un muro de capilla mayor que está flanqueado por dos puertas laterales, en cuyo centro va un altar escalonado en cuatro gradas con un sagrario en medio. A juzgar por la superposición de planos que proyecta este altar sobre la arquitectura fingida del muro, y las sombras de sus laterales, se podría pensar que es una pieza independiente de la decoración del fondo; lo que hacen de Coello un diseñador no sólo de retablos —en este caso fingido, pero con ejemplos auténticos en Ciempozuelos (Ma-

\footnotetext{
${ }^{12}$ Constan documentalmente sus trabajos sin colaboración de otros pintores en la iglesia de San Ginés y en la capilla de los siete Dolores, ambas en Madrid (h. 1685).

${ }^{13}$ Los más relevantes son los que llevó a cabo con Sebastián Muñoz en los muros de la Mantería de Zaragoza (1685) y en la Galería del Cierzo del Alcázar (1686), donde colaboraron también Palomino, Arredondo y Keseel.

${ }^{14}$ Núm.: 106272. Presenta una rotura por la parte interior. Pérez Sánchez, A. «Dibujos españoles en los Uffizi florentinos», Goya, 1972, p. 157, y Sullivan, Ob.cit. 1989, pp.269-270, donde se recoge bibliografía anterior.

${ }^{15} \mathrm{Núm}$. 317. Está pegado a otro papel y en el reverso figuran varias signaturas y una inscripción a lápiz que indica: «De Claudio Coello», Madrid, 1879. M.A. Barcia, Catálogo de la Colección de dibujos originales de la Biblioteca Nacional, Madrid 1906, pp.65-66; Sullivan, Ob.cit. 1989, pp.269, donde se recoge bibliografía anterior. Véase, además, Pérez Sánchez, Historia del dibujo en España de la Edad Media a Goya, Madrid 1986, p.286; ID, Dessins espagnols. Maitres des XV et XVII siécles. París, 1991, p.135, núm. 60.

${ }^{16}$ La hipótesis de que el dibujo de Madrid sea un calco del de Florencia se podrá ratificar cuando se superpongan ambos dibujos bajo una misma emisión de luz.

${ }^{17}$ Sobre este interesante pintor véase Álvaro Piedra, «Noticias sobre la vida y la obra de Jerónimo Ezquerra, a propósito de un cuadro suyo en el Prado», Boletín del Museo del Prado, 1985, pp.158-164. Actualmente preparo un estudio con nuevas obras suyas donde se da a conocer su nacimiento en Madrid el año 1656 y su discipulaje con Alonso del Arco, tras el que pasó once años con Juan Carreño (según documentación inédita), lo que ratifica los planteamientos del artículo anterior.

${ }^{18}$ Publicado por Mercedes Agulló, «El pintor madrileño Jerónimo Ezquerra», Villa de Madrid, 1987, pp.3-24. En él se vuelve a recoger todo lo referente a su obra, sin aportación alguna, salvo la trascripción del Inventario. Para el asiento 413, véase p. 19.
}

AEA, LXXV, 2002, 300, pp. 407 a 446 
drid) y San Esteban (Salamanca) ${ }^{19}$-, sino también de objetos litúrgicos, al modo de su maestro Rizi — recuérdese el complejo de la Sagrada Forma del Escorial-.

La composición, con un gran sentido escenográfico, heredado de su maestro Rizi, finge un balcón abierto al cielo, donde se representa una apoteosis barroca con la Inmaculada Concepción ${ }^{20}$.

Coello imagina por la parte inferior una serie de arquitecturas que comprenden el marco de los accesos laterales con frontones triangulares apoyados en ménsulas, y una media venera, por encima del altar, sobre la que irrumpe un manifestador de la Eucaristía. Tras él, corre una balaustrada, que separa a modo de un «tableau vivant» el espacio real de la iglesia del de la esfera divina, donde aparecen entre nubes los personajes de la escena. La ubicación de los objetos invadiendo los planos en una misma dimensión, como las nubes en los frontones de las puertas, la custodia sobre la media venera, pero tras el sagrario exento, o las figuras de los santos del primer término situados sobre un marco fingido en contraposición a los del segundo más arriba, ubicados tras él, hacen ratificar de nuevo que la composición de Coello se pensó para una pintura mural que a modo de un «trampantojo» simulase un mirador celestial con la oportunidad de poder contemplar el devoto la realidad viviente de una escena divina.

Supone pues un proyecto único en la pintura decorativa que se conoce de Claudio Coello, más enfocada - según indican los motivos de sus dibujos atribuidos- hacia el diseño de bóvedas, muros laterales o capillas menores, lo que viene a demostrar las posibilidades que alcanzó la pintura decorativa cortesana a finales del XVII tras la tradición de Mitelli y Colonna. Un ejemplo es la Capilla del Milagro, pintado por Rizi y Mantuano, cuyas soluciones escenográficas por medio de espacios graduados se desarrollan también en este proyecto de Coello.

Desde el punto de vista iconográfico la composición muestra también algunas singularidades interesantes. Su asunto, en efecto, con complejas alusiones teológicas, manifiesta la naturaleza inmaculada de la Virgen como Madre de Dios y tabernáculo sagrado del Cuerpo de Cristo. El tema, aunque de raíz medieval es frecuente en la devoción contrarreformista del siglo XVII, y son muchos los pintores que trataron este tema, sí bien con iconografías diversas (Herrera el Mozo, Murillo, etc.).

Comenzando la descripción de la composición por la parte central, se presenta a la Virgen Inmaculada en su habitual iconografía como Mujer del Apocalipsis, de pie sobre un creciente de luna y coronada por las doce estrellas, según la afirmación bíblica (Apocalipsis, 12.5) que refiere «dio a luz un Hijo varón, el que ha de regir a todas las naciones con cetro de hierro». $\mathrm{Su}$ silueta, girada en dos cuartos, sobre una peana de nubes que conducen veloces un corro de ángeles niños, retoma al pie de la letra — según advirtió Pérez Sánchez-el modelo de Ribera conservado antaño en la iglesia madrileña de San Pascual ${ }^{21}$. Aunque no es frecuente este tipo inmaculadista en las representaciones de Coello, no es de extrañar tampoco en su producción, habida cuenta de la frecuencia con que el pintor se inspiró en modelos de Ribera, entre ellos, la «Magdalena» de Ciempozuelos.

Esta implicación teológica de la Virgen como Madre de Dios y Tabernáculo del Cuerpo de Cristo, comienza desde el momento mismo en que una de las estrellas de su corona aparece en el centro aludiendo probablemente a María como «estrella de la mañana», anunciadora - según la letanía lauretana - de la luz de Cristo. Estas alusiones continúan siguiendo el eje vertical que proporciona la Virgen. Así, en la parte superior aparece representado el símbolo totali-

\footnotetext{
${ }^{19}$ Sobre la posibilidad de que Coello diseñase los retablos de sus grandes lienzos de altar véase A. Gutiérrez G. de Ceballos, La Iglesia y el Convento de San Esteban de Salamanca, Salamanca 1987, pp. 68-69.

${ }^{20}$ Sobre la Inmaculada Concepción en la pintura española véase Suzanne Stratton, La Inmaculada Concepción en el Arte Español, Madrid 1989.

${ }^{21}$ EXPO «El dibujo español del Siglo de Oro (Catálogo por A. Pérez Sánchez), Madrid, 1980, p. 61.
}

$A E A, \mathrm{LXXV}, 2002,300$, pp. 407 a 446 

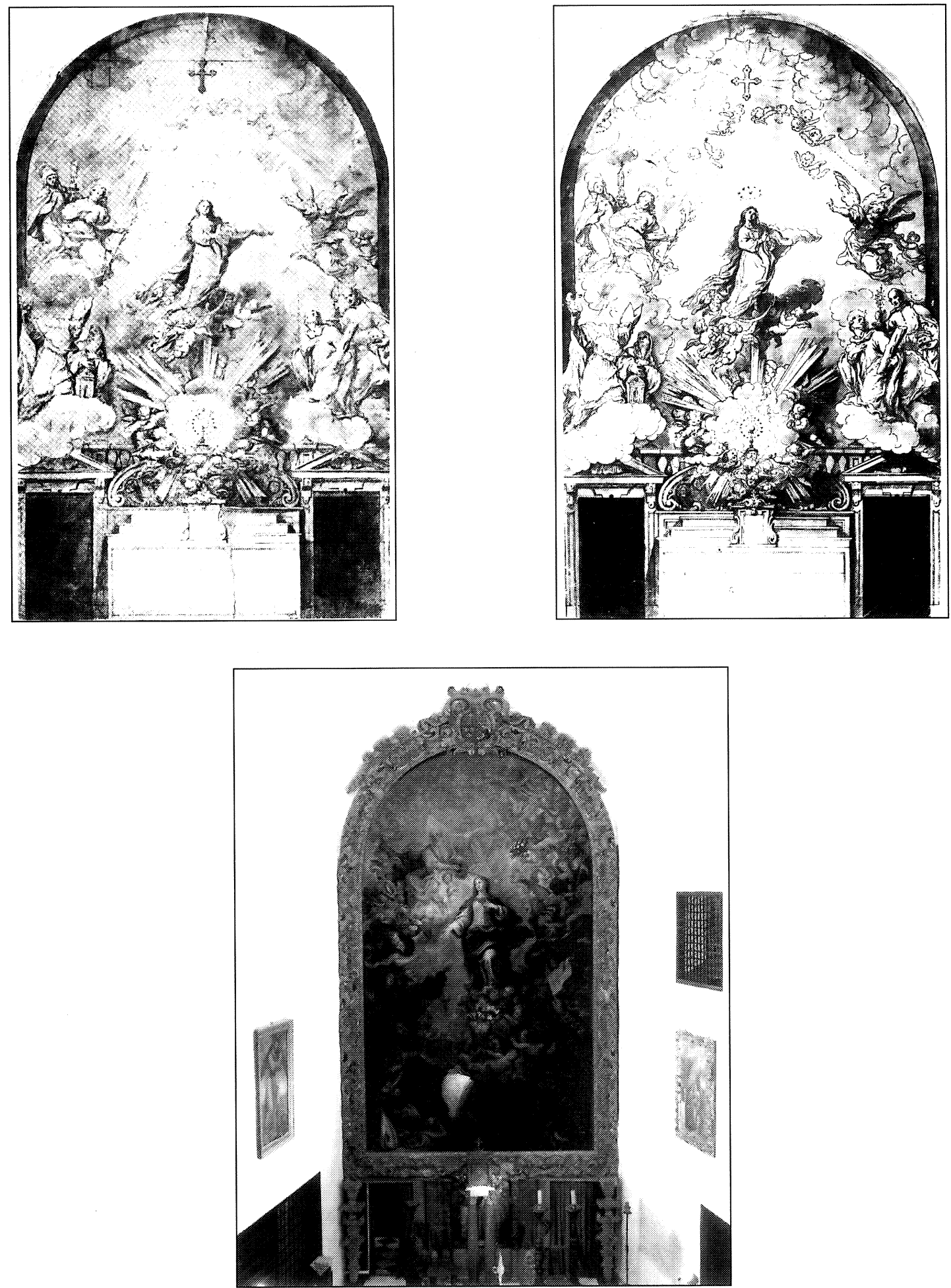

Fig. 1. Claudio Coello. Proyecto para la decoración de un muro de capilla con la Inmaculada Concepción y santos. Gabinetto Disegni e Stampe, Uffice, Florencia.

Fig. 2. Claudio Coello. Proyecto para la decoración de un muro de capilla con la Inmaculada Concepción y santos. Biblioteca Nacional, Madrid.

Fig. 3. Francisco Rizi. Inmaculada Concepción. Convento de las «Gaitanas», Toledo.

$A E A, \mathrm{LXXV}, 2002,300$, pp. 407 a 446 
zador de una cruz, unión del cielo y de la tierra, remachada con cuatro clavos, que aluden a la pasión y muerte de Cristo como redentor del género humano. En la zona inferior, aparece el Manifestador de la Eucaristía alusivo al Sacramento de la Última Cena, el cual, soportado por la cabeza de un querubín, aparece entre una explosión de nubes, de la que parten numerosos rayos sagrados, como símbolos probablemente de la divinidad contra el mal. Este manifestador se ubica ya en el espacio correspondiente de la iglesia, delante de la media venera arquitectónica, la cual podría aludir quizá al «agua de vida», y por ende al Sacramento del Bautismo. Algo más abajo, pero en la misma línea, aparece el Sagrario, como el depósito en la tierra de Cristo sacramentado.

El programa iconográfico se completa con la presencia de una serie de santos que flanquean a la Virgen por ambos lados, aludiendo al doble programa eucarístico e inmaculista del conjunto. Empezando por la parte izquierda de la composición (derecha de la Virgen) aparece sobre un cúmulo de nubes divinas la figura semiarrodillada de San Agustín, con capa pluvial y mitra, sosteniendo en su mano derecha un corazón en llamas, como emblema de su orden. Cerca de su mano izquierda aparece también un templo que alude a su primacía como Padre de la Iglesia ${ }^{22}$. Su presencia aquí se justifica por ser San Agustín uno de los mayores teólogos defensores de la Concepción Inmaculada de la Virgen. Junto a él, en estrecha comunicación visual, se presenta una figura femenina con tocas identificada como su madre, Santa Mónica, lo que podría corresponder, pues el Santo parece agradecerle su conversión cristiana indicándole con la mano izquierda el fundamento de su fe en el atributo del Templo. El valor teológico de Santa Mónica ${ }^{23}$ en esta composición podría estar en relación con el prototipo incomparable de madre cristiana, similar al de María. Tras ellos, en un plano inmediatamente superior aparece Santa Clara, de la orden de San Francisco (defensora a ultranza de la Inmaculada Concepción) con un ostensorio en la mano, aludiendo a un conocido pasaje en que por defensa de la fe cristiana puso en fuga con él, a unos invasores sarracenos. Además de esto, Santa Clara es conocida por su devoción a la Pasión de Cristo, lo que se aviene bien con el doble programa iconográfico del conjunto ${ }^{24}$. A su lado aparece San José con una rama de azucenas atributo de su castidad - aludiendo a su matrimonio místico con la Virgen, y a su paternidad jurídica pero no biológica de Jesús ${ }^{25}$. Por tanto, tendríamos aquí otro sacramento por el que se redime la concepción del género humano.

En la parte inferior derecha se representa al jesuita San Francisco de Borja —orden también defensora de la Inmaculada Concepción - sin capelo por haber renunciado a su dignidad, y acompañado de sus dos atributos más característicos, el ostensorio, por su adoración a él, y la calavera coronada, aludiendo al trance de su conversión tras contemplar el cadáver de su amada platónica la Emperatriz Isabel ${ }^{26}$. Delante de él se encuentra San Bernardo, despojado de mitra también por humilde renunciación, y caracterizado por el típico cerquillo de pelo que rodea su cabeza. La presencia de este personaje es sumamente significativa por que, sí bien, no fue un defensor de la Concepción Inmaculada de la Virgen, al proclamar su santificación después de ser concebida en el útero materno, su manifestación aquí, se justifica por ser uno de los grandes teólogos marianos que escribió sobre María como Madre de Dios - Laudibus Virginis-; desvelos que le valieron el premio de su leche materna como fuente de su elocuencia (He aquí de nuevo la exaltación en el programa iconográfico de la Virgen como Madre de

\footnotetext{
${ }^{22}$ Sobre su iconografía: Louis Réau, Iconographie de l'art chrétienne, París, 1958, Vol. 1, Tomo 3, pp. 149-156; J. Ferrando Roig, Iconografía de los Santos, Madrid 1950, p.34.

${ }^{23}$ Sobre su iconografía: Louis Réau, Ob. cit., Vol. 2, Tomo 3, pp. 960-961; J. Ferrando Roig, Ob. cit, p. 203.

${ }^{24}$ Sobre su iconografía: Louis Réau, Ob. cit., Vol. 1, Tomo 3, pp. 316-319; J. Ferrando Roig, Ob. cit, pp. 76-77.

${ }^{25}$ Sobre su iconografía: Louis Réau, $O b$. cit., Vol. 2, Tomo 3, pp. 155-171; J. Ferrando Roig, Ob. cit, pp. $152-153$.

${ }^{26}$ Sobre su iconografía: Louis Réau, Ob. cit., Vol. 1, Tomo 3, pp. 541; J. Ferrando Roig, Ob. cit., p. 114.
}

AEA, LXXV, 2002, 300, pp. 407 a 446 
Dios). Aparece sujetando en su mano izquierda un tronco de árbol como atributo de su devoción por la Pasión de Cristo ${ }^{27}$.

Encima de ellos aparece un Ángel Custodio o de la Guarda, ejecutor de la voluntad divina ${ }^{28}$. Lleva en su mano izquierda a un Niño, que alude sin duda a la naturaleza humana de Cristo. Se dirige a él, señalándole con el dedo corazón de la mano derecha, su concepción en el vientre materno de la Virgen, y con el anular el símbolo de la cruz, por la cual redimirá a los hombres.

Vemos, pues, cómo este complejísimo programa iconográfico en el que se ensalza la salvación del género humano a través de la creación Inmaculada de María como Madre de Dios, se mezcla la alegoría eucarística del Sacrificio del Cuerpo de Cristo con la redención del pecado original en la celebración de los sacramentos. Todo ello respaldado a través de las órdenes religiosas más poderosas: Agustina, Franciscana, Carmelita, Jesuita y Benedictina.

Sullivan, ha relacionado también este programa eucarístico con la devoción de las Cuarenta Horas ${ }^{29}$, habitual en los servicios litúrgicos de la Contrarreforma, y no deja de ser significativo que Coello represente aquí la exposición del Santísimo siguiendo los modelos grabados más habituales de su tiempo en este tipo de representaciones.

Ignoramos quién fue el mentor de este complejo programa iconográfico, pero ha de responder sin duda a criterios eclesiásticos de Orden religiosa (seguramente Agustina como veremos a continuación) al mezclar elementos y figuras, como Santa Clara o San Francisco de Borja que nada tienen que ver con las habituales representaciones marianas.

En lo decorativo, la composición ofrece notables diferencias con otras conocidas del artista. Es el caso del «Estudio para la decoración de la capilla de San Ignacio en el Colegio Imperial» (Uffizi, Florencia), elaborado más en la tradición decorativa de Mitelli y Colonna. Coello, en este proyecto relega los elementos arquitectónicos a unos simples marcos, necesarios por otra parte para indicar la estructura real de los accesos, pues de lo contrario sus vanos se hubiesen adornado también, ofreciendo una decoración cargada de numerosas figuras que anticipa la decoración mural posterior de Lucas Jordán tras su llegada a España en 1692. Esta composición «avivada» por las posibilidades que ofrece la pintura mural, viene a mostrar que, de haberse ejecutado se hubiera hecho al temple; técnica que, como es sabido, permite mayores efectos cromáticos que el fresco.

Como empresa decorativa no se tiene ninguna constancia documental de que se llegase a ejecutar. Aún con todo, el proyecto se ha podido relacionar verosímilmente con el testero de la Capilla Mayor del convento agustino de la Inmäulada Concepción de María, en Toledo, llamado de las Gaitanas; testero para el que precisamente su maestro Rizi, pintó en 1680 un gran lienzo de altar dedicado a la Inmaculada Concepción ${ }^{30}$ (Fig. 3).

La correspondencia del proyecto de Coello con la estructura de la capilla mayor de las Gaitanas es absoluta, no sólo en la misma disposición arquitectónica del muro con sus dos característicos accesos laterales y su cierre superior en medio punto, sino también por la temática religiosa que alude precisamente a la advocación de la citada comunidad de religiosas. Aun-

\footnotetext{
${ }^{27}$ Sobre su iconografía: Louis Réau, Ob. cit., Vol. 1, Tomo 3, pp. 207-217; J. Ferrando Roig, Ob. cit, p. 61. Aunque no es frecuente representar a San Bernardo con un tronco de árbol, la identificación del personaje en este contexto no ofrece dudas, al ajustarse como teólogo de la Madre de Dios, y adorador de la Pasión de Cristo. Por otra parte, es significativo que algunos árboles sean tenidos simbólicamente como «dadores de niños», lo que se ajusta bien con el siguiente paso iconográfico.

${ }^{28}$ Sobre su iconografía: Louis Réau, Ob. cit., Vol. 1, Tomo 2, pp. 35-36.

${ }^{29}$ Sullivan, $O b$. cit., 1989, p. 269. Sobre esta devoción léase el interesante artículo de Mark S. Weil, «The Devotion of the Forty Hours and Roman baroque illusions», Journal of the Warbug and Courtauld Institutes, 1974, pp. 218-248.

${ }^{30}$ Sobre este cuadro véase A. Pérez Sánchez, La Inmaculada Concepción de Francisco Rizi del Convento de las Gaitanas de Toledo, Toledo, s.f. (1995).
}

$A E A$, LXXV, 2002, 300, pp. 407 a 446 
que el muro de la capilla del convento parece más estrecho que en el proyecto, esto podría deberse en parte al efecto óptico reductor que produce el ancho marco que rodea al lienzo parcialmente omitido en los dibujos de Coello. En cuanto a la cronología, la composición de Coello se aviene también con la fecha del cuadro de Rizi, al reflejar una serie de tecnicismos, como el perfil de San Agustín, similar al de San Pablo del dibujo grabado para el frontispicio de la obra de «El Buen Pastor» de Francisco Núñez de Cepeda (1683) ${ }^{31}$.

Cabe entender pues que el estudio de Coello se realizó para la decoración de esta capilla mayor, apalabrándose antes que el lienzo de Rizi. Y que -de ser así- por alguna extraña razón, el trabajo se traspasó finalmente a su maestro. La causa de esta hipotética cesión no es fácil de explicar, sino es en función de una «asociación» profesional entre ambos artistas. Son muchos los ejemplos, en los que Coello o Rizi parecen haberse cedido mutuamente sus trabajos en circunstancias poco claras para nosotros. Incluso algunas de ellas por motivos económicos. Recuérdese la anécdota que refiere Palomino sobre uno de los primeros trabajos de Coello: el retablo mayor de la iglesia de Santa Cruz, en el que al parecer Rizi, ofreció su nombre, (es decir, su firma) para que Coello obtuviese más dinero por él ${ }^{32}$. Este juego de cesiones (o influencias en muchos casos por parte del maestro) se advierte también en el encargo de Coello para la decoración del altar mayor de la iglesia de San Plácido (1668), donde Rizi, siguiendo un programa decorativo iniciado en 1658, había pintado ya la cúpula y las pechinas hacia 1660$1661^{33}$. Caso aún más evidente es el del altar de la Sagrada Forma del Escorial, cedido a Coello en 1685 por la muerte de su maestro..

Tras esto - y siguiendo con el supuesto destino del proyecto de Coello- cabe plantearse si el encargo de las Gaitanas fue fruto del taller de Rizi o de Coello. Aunque ambos artistas participaron como es lógico de los mismos comitentes al ser maestro y discípulo, la orden Agustina no parece ser, sin embargo, el cliente habitual en los encargos de Rizi, y sí en los de Coello. Baste señalar sus trabajos para el convento de agustinos recoletos de Alcalá de Henares (1664), o sus pinturas murales para la iglesia del antiguo convento de agustinos o de la «Mantería», en Zaragoza (1683-1685).

En cualquier caso, los trabajos del pintor para Toledo tampoco son extraños en su producción. Coello, probablemente por influencia de Rizi, había decorado en colaboración con Donoso el Vestuario de la Catedral (1671-1674) ${ }^{34}$, llegando a ser posteriormente su «pintor principal» en $1691^{35}$.

Sea como fuese, este proyecto de Claudio Coello supone un eslabón más en su producción artística, imprescindible para comprender desde luego cual fue realmente su significación como decorador mural.

Álvaro Piedra Adarves

\footnotetext{
${ }^{31}$ Sullivan, Ob. cit. 1989 , pp. 262 y 285

${ }^{32}$ Palomino, $O b$. cit., T. 3, p. 452. Sobre esta anécdota véase Ismael Gutiérrez, «Francisco Rizi y Claudio Coello. A propósito de la anécdota de Palomino sobre el Retablo de la Parroquia de Santa Cruz de Madrid», Anuario del Departamento de Historia y Teoría del Arte, núm. 45-46, 1992, pp. 231-237.

${ }^{33}$ Las obras de este retablo se suspendieron - como es sabido - hasta la retoma de Coello. Ismael Gutiérrez ha hecho una revisión sospechando la cesión del encargo en «Art.cit.», pp. 232-234.

${ }^{34}$ Recuérdese que Rizi fue nombrado pintor de la Catedral de Toledo en 1653, y que sus trabajos para ella fueron constantes hasta el final de su vida: lienzos, frescos (Capilla del Ochavo y su Camarín, en colaboración con Carreño hacia 16651670), Monumento de Semana Santa, etc. Además, Rizi pintó para otros lugares: Burguillos y Orgaz.

${ }^{35}$ Ceán Bermúdez, Ob.cit., T. 1, p. 342. Otros trabajos del pintor son los lienzos del retablo de la parroquia de Nuestra Señora de la Asunción, en Calzada de Oropesa.
}

AEA, LXXV, 2002, 300, pp. 407 a 446 